\title{
FORMAÇÃO PROFISSIONAL E DESENVOLVIMENTO LOCAL: RELAÇÕES E OPORTUNIDADES A PARTIR DA ELABORAÇÃO DO PROJETO EDUCATIVO DE UM MUNICÍPIO PORTUGUÊS
}

\author{
Joaquim Luís Medeiros Alcoforado ${ }^{1}$ \\ Mafalda Frias ${ }^{2}$ \\ António Manuel Rochette Cordeiro ${ }^{3}$
}

\begin{abstract}
RESUMO
As políticas de formação profissional, ao alinharem-se com as inovações tecnológicas, transformações produtivas e com a organização do trabalho, procuram definir estratégias que resultem numa efetiva participação do indivíduo no seu ambiente produtivo. Com uma intenção integradora e, tendo em consideração as mudanças dos processos e contextos dos setores da economia, as entidades de formação profissional, ao adotarem uma visão mais ampla de ação deverão orientar-se para o desenvolvimento de iniciativas formativas ajustadas às reais necessidades da sociedade e, principalmente, da comunidade local, na qual os cidadãos atuam. Nesta linha de pensamento, no âmbito de um projeto estratégico para a educação em contexto municipal - Projeto Educativo Local desenvolvido entre a Universidade de Coimbra e um município da Área Metropolitana de Lisboa (Sintra), e ainda numa fase de diagnóstico, recorrendo à técnica Grupo Focal, foi realizada uma auscultação da perceção de representantes das empresas e entidades de formação do território municipal em torno da caracterização do tecido empresarial e suas necessidades ao nível dos recursos humanos e respetivas áreas de formação. Partindo do pressuposto de que o desenvolvimento local apela à participação de todos os agentes e de todas as pessoas, a partir de uma preparação holística, a formação profissional, enquanto contributo vital para o desenvolvimento económico, social e cultural, torna-se um fenómeno multidimensional focado, essencialmente, na promoção de capacidades de ação e no reforço das condições de participação individual e grupal, nos processos de desenvolvimento integrado e sustentado, a partir das realidades das pessoas e das suas comunidades.
\end{abstract}

Palavras-chave: Projeto educativo local. Formação profissional. Parcerias e desenvolvimento local.

\section{PROFESSIONAL EDUCATION AND LOCAL DEVELOPMENT: RELATIONSHIPS AND OPPORTUNITIES DERIVED FROM THE EDUCATIONAL PROJECT OF A PORTUGUESE MUNICIPALITY}

\footnotetext{
ABSTRACT

${ }^{1}$ Doutor em Ciências da Educação pela Universidade de Coimbra, Professor na Faculdade de Psicologia e de Ciências da Educação da Universidade de Coimbra e Investigador do Grupo de Políticas Educativas e Dinâmicas Educacionais (GRUPOEDE) do Centro de Estudos Interdisciplinares do Século XX (CEISXX). Coordenador do Mestrado em Ciências da Educação e Membro da Comissão de Coordenação do Doutoramento em Ciências da Educação, da Faculdade de Psicologia e de Ciências da Educação da Universidade de Coimbra. Email: lalcoforado@fpce.uc.pt

2 Doutoranda em Ciências da Educação - Especialidade em Educação, Desenvolvimento Comunitário e Formação de Adultos, Universidade de Coimbra. Mestra em Ciências da Educação - Educação e Formação de Adultos. Licenciada em Ciências da Educação. Bolseira de Investigação da Fundação para a Ciência e a Tecnologia (FCT). Email: friasmafalda@gmail.com

${ }^{3}$ Doutor em Geografia e Professor Catedrático do Departamento de Geografia e Turismo da Universidade de Coimbra - 1. ${ }^{\circ}$ Ciclo de Estudos, programas de Mestrado e Doutoramento em Geografia e Estudos do Uso do Solo e Ambiente - e do Mestrado Integrado do Departamento de Arquitectura (FCTUC). Coordenador Científico do Centro de Estudos Interdisciplinares do Século XX (CEIS20-IIIUC). Coordenador da Unidade de Investigação "Territórios e Educação "E Diretor do Programa de Mestrado" Geografia Física, Meio Ambiente e Uso do Solo ”. É também Diretor da Revista “Estudos do Século XX”.Email: rochettecordeiro@fl.uc.pt
} 
By combining professional training policies with technological innovations, changes in production and work organization seek to define strategies that result in the individual's effective participation in their production environment. With an integrative intention and by taking into account the processes and contexts' changes of the economy sectors, professional training entities should, by adopting a broader view of action, focus on the development of training initiatives adjusted to society's real needs and, specially, adjusted to the local community in which the citizens act. As a result, within a municipal context's education strategic project - Local Educational Project - developed between the University of Coimbra and a Lisbon's Metropolitan Area County (Sintra), still in a diagnostic phase and by using the Focus Group technique, some companies and training institutions representatives of the territory counties were heard about the business characterization and its needs in terms of human resources and training areas. Assuming that local development calls for the participation of all agents and all people, based on a holistic preparation, professional education, as a vital contribution to economic, social and cultural development, becomes a multidimensional phenomenon essentially focused on promoting action capacities and strengthening the conditions for individual and group participation, in the processes of integrated and sustained development, based on the realities of people and their communities.

Keywords: Local educational project. Professional education. Partnerships and local development.

Data da submissão 15.10 .2020

Data da aprovação 07.12.2020

\section{INTRODUÇÃO}

\section{FORMAÇÃO PROFISSIONAL EM PORTUGAL- BREVE CONTEXTUALIZAÇÃO}

As políticas educativas portuguesas ganham especial enfoque em 1986, ano que ficou marcado por dois acontecimentos charneira, "com repercussões que podemos considerar muito importantes para a evolução futura do sistema de ensino, particularmente, para a componente técnica e profissional" (PARDAL et al., 2003, p. 105). Se, por um lado, assistimos à aprovação em 14 de outubro, da Lei de Bases do Sistema Educativo (LBSE), que definiu o enquadramento legal para a educação, nomeadamente, estabilizando o lugar do ensino técnico e profissional de nível secundário, por outro lado, verifica-se a integração de Portugal na então Comunidade Económica Europeia, facto que se assumiria como de extrema relevância, designadamente, para o financiamento da formação profissional para jovens e adultos (ALCOFORADO et al., 2013) com o objectivo, explicitamente enunciado, de incrementar a produtividade do trabalho e a competitividade da economia.

A formação profissional surgiu, deste modo, com a pretensão de se adequar "às necessidades conjunturais nacionais e regionais de emprego", sendo "dever das escolas básicas e secundárias do país assegurar o funcionamento destes cursos" destinados a jovens que frequentavam o ensino básico e secundário, através do estabelecimento de protocolos de colaboração com o tecido empresarial e as autarquias locais, fomentando uma ligação entre a formação e o emprego (RODRIGUES, 2011, p. 46). A LBSE, na sequência deste processo de reconstrução da oferta de formação profissional inicial, possibilitou, igualmente, o aparecimento de Escolas Profissionais de iniciativa privada, apoiadas pelo Estado Português e pela União Europeia (UE), criadas pelo Decreto-Lei no 26/89, de 21 de janeiro (PORTUGAL, 1989). A criação destas escolas constituiu-se, desta forma, como um instrumento essencial para a afirmação do ensino profissionalmente qualificante, como modalidade alternativa ao ensino secundário regular (DIAS, 2012).

No âmbito da Revisão Curricular dos Ensinos Básico e Secundário, consagrada no Decreto-Lei $\mathrm{n}^{\circ}$ 286/89, de 29 de agosto, prevê-se que o ensino secundário se organize numa estrutura curricular constituída por três componentes: "geral ou sociocultural, específica ou 
científica e técnica ou tecnológica, variando o peso de cada componente de acordo com a tipologia do curso", situação que se mantém até 2004 (fase de nova reforma do ensino secundário), em cursos predominantemente orientados para o prosseguimento de estudos - os cursos gerais - e cursos predominantemente orientados para o ingresso na vida ativa - os cursos tecnológicos (CERQUEIRA \& MARTINS, 2011). Para além das iniciativas levadas a cabo pelo Ministério da Educação, no âmbito dos ensinos básico e secundário, há que salientar a experiência acumulada nesta área, mormente através dos cursos de formação em alternância, pelo Instituto do Emprego e Formação Profissional (IEFP), sob a tutela do Ministério da Segurança Social e do Trabalho.

As Escolas Profissionais surgem, portanto, na sequência das tendências verificadas a partir da década de oitenta, nas políticas educativas portuguesas, numa situação favorável de existência de recursos económicos (provenientes dos fundos estruturais da, então, Comunidade Económica Europeia para a formação profissional), sendo encaradas como uma via alternativa de ensino secundário, "de iniciativa eminentemente local" para os jovens que tivessem concluído o $9^{\circ}$ ano de escolaridade. Tal como se enunciava nas decisões políticas, com as Escolas Profissionais (Decreto-Lei n 26/89, de 21, de janeiro, Art $^{\circ} 3^{\circ}$ ) pretendia-se,

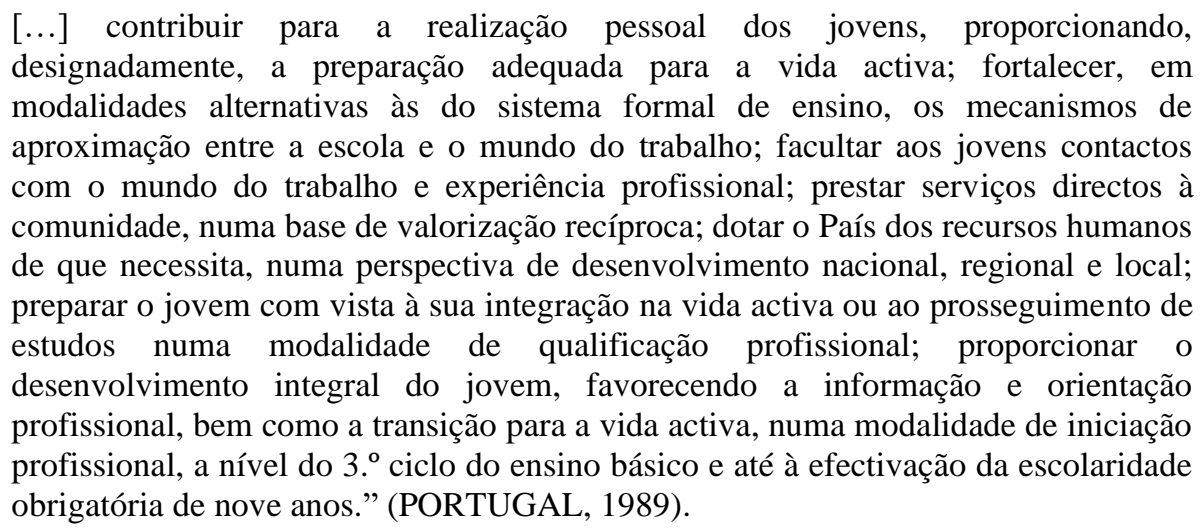

O surgimento do ensino técnico e profissional era, então, apresentado com o objetivo primordial de fornecer ao mercado de trabalho mão-de-obra especializada, através de profissionais de nível intermédio, com uma boa formação integral, permitindo contribuir para o desenvolvimento socioeconómico do país, para a minimização do desemprego jovem e para a redução do insucesso e abandono escolares. Anteriormente, o ensino técnico e profissional sempre esteve associado a um meio de seleção escolar precoce, que reproduzia a origem social (já que os jovens pertencentes às classes mais baixas eram "orientados" para esta tipologia de ensino, tendo em vista a necessidade de um emprego a curto prazo) e promovia uma formação sem grandes possibilidades de continuidade, não dando, de forma primordial, acesso direto ao ensino superior contribuindo, assim, para a ideia de um ensino desprestigiado. Estas iniciativas procuravam fazer estes percursos valer pela sua qualidade intrínseca, devendo constituir-se como uma via com igual dignidade, sendo, por isso mesmo, uma opção entre outras.

Se é certo que entre o legislado e o conseguido existiu sempre uma distância muito considerável, ao longo dos últimos anos, na sequência de compromissos internacionais e do esforço para garantir o ensino secundário como nível mínimo de formação para todos os portugueses, o ensino profissionalizante, mesmo que nunca tenha sido alcandorado ao mesmo prestígio e dignidade de outras vias, passou a envolver mais de metade dos jovens portugueses do ensino secundário, tendo-se procedido a uma reformulação dos objetivos e conteúdos curriculares, procurando reforçar, progressivamente, o reconhecimento social do ensino técnico e profissional, como uma alternativa credível, proporcionando, inclusivamente, possibilidades de continuação para o ensino superior. 
Estamos, portanto, na actualidade (PELIZ, 2014), perante uma via de ensino secundário que se alarga a dimensões profissionais, desportivas e artísticas, procurando contribuir decisivamente para o cumprimento da escolaridade obrigatória (entretanto, aumentada para doze anos), sendo capaz, em simultâneo, de proporcionar oportunidades a diferentes níveis, nomeadamente o prosseguimento de estudos e a perspetiva de desenvolvimento pessoal e social, mas sempre com a finalidade central de preparar para o incremento da empregabilidade, formando trabalhadores capazes de aumentar a produtividade do trabalho e das empresas.

No que concerne à formação profissional, para pessoas adultas, a adesão de Portugal à Comunidade Económica Europeia, constituiu, igualmente, um momento fundacional de novas opções e de concentração de recursos para enfrentar novas prioridades (CRUZ et al., 2013). $\mathrm{Na}$ verdade, se da aposta na formação de jovens poderíamos esperar, na lógica da dimensão ideológica predominante, um futuro com maior produtividade do trabalho e uma economia mais competitiva, a dimensão dos défices que Portugal apresentava, em relação aos seus parceiros do novo bloco económico, nos indicadores que eram privilegiados pelas políticas europeias, eram tão significativos que se tornava urgente empreender mudanças imediatas. E essas, naturalmente, só poderiam advir do investimento na formação das pessoas em idade ativa.

Foram, então, disponibilizados meios muito significativos, primeiro, para uma formação profissional muito próxima das, eventuais, necessidades das empresas e depois, já no final do século passado e início deste século, orientadas para uma aposta muito forte na elevação dos níveis de qualificação da população portuguesa, considerando ser esse o melhor preditor para, em simultâneo, atender às necessidades de aumentar a empregabilidade, promover a mobilidade e contribuir para uma economia competitiva, mais suportada no conhecimento e em contributos mais intelectuais.

Já no presente século, torna-se imperativo atribuir particular destaque à Resolução do Conselho de Ministros n. ${ }^{\circ}$ 173/2007 (PORTUGAL, 2007), que aprovou uma nova reforma da formação profissional. A Iniciativa Novas Oportunidades surgiu (ALCOFORADO et al., 2018), nesse contexto, como uma estratégia direcionada para a concretização de um amplo conjunto de reestruturações que, na verdade, vinham colocar novas ambições e disponibilizar novos recursos para os objectivos já enunciados para o sistema de formação profissional, suportando-se em dois pilares fundamentais.

Em primeiro lugar, visava fazer do ensino profissionalizante, de nível secundário, uma verdadeira e real opção, dando oportunidades novas aos jovens. O segundo pilar estava voltado para elevar a formação de base dos ativos (ALCOFORADO, 2008; ALCOFORADO et al., 2018; ALCOFORADO et al., 2020). Para estas duas dimensões são estabelecidas metas muito ambiciosas, enunciando uma absoluta profissão de fé na necessidade de elevar definitivamente os níveis de qualificação da população e no conhecimento como base para a transformação desejada dos processos produtivos.

Em síntese, era declarada a intenção de que toda a formação pudesse assegurar uma progressão escolar e profissional, aumentando a sua relevância para a modernização empresarial, através de uma agenda reformista centrada em cinco linhas fundamentais: estruturar uma oferta formativa, relevante e certificada; reformar as instituições e a regulação da formação; definir prioridades e modelos de financiamento adequados; promover a qualidade da formação e facilitar o acesso e promover a procura da formação (PORTUGAL, 2007).

Como tem sido demonstrado (ALCOFORADO et al., 2018), as políticas de Educação e Formação de Adultos, em Portugal, se têm vindo a revelar alguma persistência em termos de recursos disponíveis e finalidades enunciadas, do ponto de vista das iniciativas nacionais e da organização, têm reflectido, de forma recorrente, as sensibilidades dos diferentes governos, 
bem como das respectivas prioridades nos processos negociais dos contratos-programa plurianuais com a União Europeia. Ainda que no caso dos jovens se consiga identificar uma certa persistência do essencial das opções políticas, no caso das pessoas adultas foram sendo registradas demasiadas oscilações para que hoje possamos assinalar a existência de uma política estável e previsível. Em qualquer dos casos, contudo, nos anos mais recentes, mantendo-se o essencial das dimensões ideológicas, também se criaram condições para um evidente reforço da centralidade discursiva e de práticas com um novo apelo à participação do poder e sociedade civil locais.

Têm sido, exactamente, estas novas responsabilidades e competências atribuídas e assumidas pelos municípios, também no domínio da formação profissional, que nos tem ocupado ao longo dos anos mais recentes, em diferentes trabalhos colaborativos de pesquisa e elaboração de políticas de base local. Fomos assumindo a necessidade de reequacionar os pressupostos de elaboração dos princípios orientadores de novas opções, partindo de um entendimento alargado sobre a relação da educação com o desenvolvimento local, acreditando que as políticas públicas municipais devem resultar de uma articulação entre diferentes parceiros, constituindo-se como um instrumento facilitador das dinâmicas das pessoas e das diferentes comunidades que elas integram.

\subsection{FORMAÇÃO PROFISSIONAL E DESENVOLVIMENTO LOCAL}

O binómio educação e trabalho sempre deixou transparecer uma relação controversa, complexa e dialética, desafiando a que sejam considerados os princípios educativos e formativos, independentes e resultantes da interceção dos dois campos, os vínculos entre vida produtiva, ciência, cultura e humanismo e levando à necessidade de assumir, em primeiro lugar, o entendimento da formação profissional, como um fator determinante do processo de construção de conhecimentos totalizadores e libertadores do sujeito integrado numa determinada comunidade.

Associada a esta relação entre educação e trabalho encontra-se a necessidade do desenvolvimento socioeconómico, político e cultural da sociedade, o qual necessita de um tempo e de um espaço para acontecer, relacionados diretamente com a procura de formas integradas e sustentadas de desenvolvimento local (PIVETEAU, 2010; ALCOFORADO et $a l ., 2014)$, devendo a formação profissional impulsionar o aparecimento de indivíduos críticos e conscientes das relações que se estabelecem no mundo do trabalho (SOUZA, 2011) e nos contextos territoriais, onde todas as dimensões da vida acontecem.

A compreensão do desenvolvimento local, a partir da educação, pressupõe a aceitação de que o pensamento recebe influência do contexto, sendo esta ideia reforçada por Freire (1983, p.17), ao afirmar que "como não há homem sem mundo, nem mundo sem homem, não pode haver reflexão e ação fora da relação homem-realidade". Assim, para o mesmo autor, faz parte do leque de responsabilidades da escola potenciar o despertar crítico do indivíduo e trazer à realidade este "homem" no seu mundo, com o compromisso de organizar os seus "saberes históricos e escolares", estruturando currículos de maneira a considerarem saberes significativos para este indivíduo e sua comunidade, de forma que se internalizem as transformações sociais e culturais da sociedade envolvida, numa conceção de interação com o seu meio.

Através da formação e da educação, o indivíduo constrói-se e reconstrói-se, adapta-se e transforma as condições dadas pelo seu contexto social, enfrenta desafios pessoais e coletivos, devendo assumir-se como agente de desenvolvimento, em termos pessoais e sociais. Dito de outra forma, acredita-se que a apropriação do saber pelo indivíduo provoca direta e efetivamente o progresso de uma comunidade (profissional, cultural, de 
vizinhança...), ajudando a dar sentido às aspirações e projetos dos seus membros, humanizando-os e humanizando as suas diferentes ações.

Olhando de um outro viés, a sociedade atual vem-se caracterizando por céleres mudanças tecnológicas, sociais e económicas, sendo hoje atribuído aos sistemas educativos, pelas diferentes instâncias de poder, o mandato de acompanhar ou antecipar essas transformações. Assiste-se, assim, nos últimos anos, a uma mudança das relações educaçãoeconomia e educação-mercado de trabalho, na qual vão sendo definidos, continuamente, novos perfis escolares e profissionais.

Por um lado, as idiossincrasias da globalização económica e as ambições competitivas das economias apelam ao reforço das competências relacionadas com a produtividade do trabalho, enquanto, ao mesmo tempo, o conhecimento das Ciências da Formação procuram, ainda que timidamente, influenciar políticas públicas promotoras de dimensões mais qualitativas e de contracorrente, alargando o conceito de formação profissional para lá de um alinhamento natural com as transformações produtivas, as inovações tecnológicas e com a organização do trabalho, mas, principalmente, possibilitando experiências educativas mais holísticas, capazes de preparar os/as trabalhadores/as para uma acção responsável e autónoma na transformação dos seus diferentes contextos de vida.

Desde há várias décadas, como oportunamente lembrou Lesourne (1988), que os desafios económicos estão a exigir, tanto a nível individual como coletivo, um aumento considerável das competências da população ativa, jovem ou adulta. Este facto remete para uma "melhoria na formação geral dos jovens, no sentido de desenvolver as atitudes e aptidões desejáveis, uma formação profissional facilitadora do acesso ao primeiro emprego, tendo em conta que esta será tanto mais frágil quanto mais especializada, e, por último, uma formação contínua que acompanhe o indivíduo ao longo do seu desenvolvimento profissional e pessoal" (MADEIRA, 2006, p. 124).

É, então, crucial e determinante proporcionar aos jovens uma formação inicial que assegure uma base cultural e técnico-científica alargada que possibilite a adaptabilidade e a mobilidade exigidas numa sociedade em constante mudança. Para além da preparação para o exercício de uma atividade profissional, é essencial atender a dimensões como a inovação, a iniciativa e a aprendizagem ao longo da vida. A este nível ressalta a importância das competências transversais, como são exemplo a criatividade, a capacidade de comunicação e de resolução de problemas, a capacidade de trabalhar em equipa e de avaliar as contínuas situações de imprevisibilidade com que, inevitavelmente, se irão deparar (AZEVEDO, 1991).

Um tal entendimento de formação obriga a uma relação mutuamente desafiante com um projecto de desenvolvimento local ideologicamente consonante e, por maioria de razão, impele à construção de comunidades locais de educação e formação, integradas por todos os parceiros, capazes de garantir a diversidade e continuidade de experiências que estas opções holísticas, integradas e transformadoras exigem. Por isso mesmo, pensar e planear políticas locais exige o compromisso de escutar todos os parceiros e criar hábitos de diálogo e trabalho conjunto para encontrar novas respostas, baseadas em processos mais democráticos, específicos, participados e inovadores.

Conscientes desta necessidade e obrigação, e no âmbito dos trabalhos para a elaboração de um plano estratégico educativo municipal, foram implementadas metodologias participativas de envolvimento de todos os agentes, dando nota, neste artigo, das perceções iniciais de um grupo de representantes das empresas e instituições de formação do Município de Sintra, ao nível das necessidades e da disponibilidade para o envolvimento sincero numa outra forma de planear e desenvolver actividades de formação de jovens e adultos. 


\section{METODOLOGIA}

$\mathrm{Na}$ sequência do desafio lançado aos municípios portugueses para assumirem responsabilidades e competências, no domínio da educação, foi sendo criada a necessidade de ser desenvolvido, por cada executivo municipal, um planeamento estratégico, primeiro, no domínio da rede escolar e, depois, de todas as ações que se deseja que possam vir a contribuir para o início da configuração de uma real política local de educação e formação profissional.

Dando sentido a estes reptos e obrigações e corporizando a vontade de pensar estrategicamente a evolução da educação, a nível municipal, foi desenvolvido um trabalho conjunto entre uma equipa de investigação interdisciplinar da Universidade de Coimbra e o Departamento de Educação do Município de Sintra e respectivos responsáveis políticos e diferentes agentes com ação e interesse nesta temática, nesse espaço territorial, que resultou em diagnósticos circunstanciados da realidade existente e se propôs elaborar um projeto com um sentido e recursos para o prosseguir, capaz de se traduzir como denominador comum de aspirações e vontades no âmbito educativo, para o curto e o médio prazo - Projeto Educativo Local (PEL).

Assumindo este planeamento estratégico no âmbito da educação, para além das suas funções tradicionais, o Município acumula a responsabilidade de desenvolvimento permanente de uma função educadora, orientada para a formação, promoção e desenvolvimento de todos os cidadãos e das respectivas comunidades, tornando-se essencial desenvolver práticas ecoeducativas capazes de permitir que todos aprendam em conjunto, nos seus espaços e em todas as idades da vida, num desafio indutor de desenvolvimento integrado e sustentável com o meio em que vivem e que partilham.

Neste processo, a articulação entre as organizações educativas e outros parceiros locais com responsabilidades no sucesso do cidadão municipal revela-se determinante, na medida em que, esta visão estratégica da educação e da formação, procura potenciar todos os recursos educativos do território para construir o melhor caminho que responda à necessidade de uma formação humanista integral, que incremente a criação de riqueza, com emprego digno, multiplique as oportunidades de acesso e produção de bens culturais e vise um bem-estar individual e coletivo, ancorado na ambição da construção continuada de um Município inteligente, inovador, inclusivo e participado.

O planeamento do Projeto Educativo Local (PEL), suportado por todas estas características e convicções, assentes nas necessidades dos cidadãos e, concludentemente, num quadro desejável com todos e para todos, suportou-se numa metodologia totalmente participada, ao longo das diferentes etapas do processo. Não obstante o alargado conjunto de procedimentos metodológicos elencados na construção do PEL, atendendo às diferentes áreas temáticas e respetivos parceiros locais, neste trabalho, em concreto, centramo-nos, exclusivamente numa das dimensões do eixo estratégico do trabalho, qualificação e inovação.

Neste sentido, considerando a importância que o tecido empresarial encerra no desenvolvimento concelhio, ainda numa fase de diagnóstico do PEL, através de um Focus Group, foi proposto a diferentes entidades locais de âmbito empresarial e com intervenção ao nível da qualificação da população jovem e adulta, um momento de reflexão conjunta em torno das características do tecido empresarial do município e respectivas necessidades de formação.

Para esta etapa do diagnóstico e, atendendo ao vasto número de atores implicados neste processo (empresários), com a colaboração do Gabinete de Apoio Empresarial do Município, foi estabilizada a participação de vinte e quatro elementos, entre representantes do tecido empresarial e entidades promotoras de formação do município. Tendo em consideração o elevado número de elementos, optou-se por formar dois grupos de doze participantes, 
elegendo uma abordagem moderadamente estruturada, cujo guião de debate terá assumido a forma de um conjunto de linhas orientadoras para a discussão pretendida.

Assim, foram lançadas várias questões para reflexão: $\mathrm{O}$ que podemos dizer do tecido empresarial do concelho? E sobre a sua evolução a curto e médio prazo? Como podemos perspectivar a sua evolução em termos de qualificações? De que trabalhadores necessitam as empresas do concelho em termos de formação geral e formação técnica específica? Como podem ser formados esses trabalhadores? Que contributos podem dar as empresas na formação inicial de jovens, na formação contínua e em programas de informação profissional para os adolescentes das escolas do município?

\section{RESULTADOS}

Tendo como referência algumas das linhas orientadoras de reflexão e debate lançadas aos representantes das empresas e entidades de formação do concelho, antecipadamente, torna-se possível estruturar a informação recolhida por blocos temáticos, os quais permitirão evidenciar algumas das características do tecido empresarial do município, bem como principais lacunas e necessidades sentidas no âmbito da formação dos seus recursos humanos. Assim, de forma a facilitar a análise dos dados recolhidos optou-se pela construção de um quadro que sintetiza as áreas temáticas abordadas, unidades de registro e exemplos de transcrições das declarações dos participantes (Tabela 1).

Uma análise global das diversas intervenções das entidades presentes tornou visível a opinião generalizada no que concerne à pouca atratividade e falta de mão-de-obra no setor da indústria, resultando em entraves ao nível dos processos de "recrutamento de recursos humanos qualificados" (nomeadamente, jovens) em áreas técnicas (e.g. serralharia, mecânica, canalização, soldadura, química, manutenção industrial, carpintaria, eletricidade, mecatrónica, entre outros), principalmente, quando surgem picos de produção.

A mobilidade dos trabalhadores constituiu mais uma das temáticas evidenciadas por vários empresários, tendo estes referido que a ausência de transportes públicos, em determinadas zonas do concelho, torna a viatura própria um requisito obrigatório para a admissão de recursos humanos. Tal facto traduz-se numa acentuada dificuldade no que diz respeito aos processos de recrutamento.

No âmbito dos cursos profissionais foi referido o facto de alguns deles terem sido extintos, com particular ênfase na área da química, colocando ao dispor das empresas apenas licenciados e mestres em áreas afins, o que não corresponde às suas necessidades. Importante será também mencionar a disponibilidade manifestada pelas empresas para apoiar as Escolas Profissionais na criação de cursos/ações de formação voltadas para as áreas em análise.

Tabela 1. Organização da informação recolhida - Temas, unidades de registo e principais indicadores

\begin{tabular}{|c|c|c|}
\hline Temas & $\begin{array}{l}\text { Unidades } \\
\text { de Registo }\end{array}$ & Exemplos \\
\hline Setor industrial & 8 & $\begin{array}{l}\text { "(...) pouca atratividade e falta de mão de obra. Temos dificuldade } \\
\text { em recrutar jovens para áreas técnicas, principalmente quando } \\
\text { surgem picos de produção". }\end{array}$ \\
\hline Mobilidade & 3 & $\begin{array}{l}\text { "Não existe transporte público em algumas zonas, o que dificulta } \\
\text { bastante a vida de quem procura trabalho (...)". }\end{array}$ \\
\hline profissionais & 4 & $\begin{array}{l}\text { "Alguns cursos profissionais simplesmente deixaram de existir, } \\
\text { como por exemplo, a química (...) acabamos por apenas ter ao } \\
\text { dispor licenciados e mestres em áreas afins". }\end{array}$ \\
\hline Falta de reconhecimento & 6 & “(...) hoje em dia ainda é evidente o estigma associado ao ensino \\
\hline
\end{tabular}




\begin{tabular}{|c|c|c|}
\hline do Ensino Profissional & & $\begin{array}{l}\text { profissional e áreas técnicas (...) é preciso atuar, trabalhar para o } \\
\text { reconhecimento social do ensino profissional e de algumas } \\
\text { profissões". }\end{array}$ \\
\hline $\begin{array}{l}\text { Formação prática no } \\
\text { Ensino Profissional }\end{array}$ & 5 & $\begin{array}{l}\text { "Falta prática nestes cursos, é um facto (...) é essencial aumentar as } \\
\text { atividades dentro das empresas". }\end{array}$ \\
\hline Estágios-Emprego (IEFP) & 5 & $\begin{array}{l}\text { "O processo para financiamento de um estágio profissional é } \\
\text { extremamente lento (...) é urgente criar estratégias que permitam } \\
\text { agilizar todo este processo". }\end{array}$ \\
\hline Competências transversais & 3 & $\begin{array}{l}\text { "Sentimos grandes lacunas nas competências pessoais e sociais dos } \\
\text { jovens }(\ldots) \text { ". }\end{array}$ \\
\hline $\begin{array}{l}\text { Colaboração Empresas - } \\
\text { Escolas Profissionais }\end{array}$ & 6 & $\begin{array}{l}\text { “A nossa empresa está completamente disponível para colaborar } \\
\text { com as escolas profissionais no sentido da criação de ações de } \\
\text { formação voltadas para estas áreas" } \\
\text { “ (...) e portanto, reconhecemos a necessidade de ajustar a } \\
\text { formação às necessidades das empresas. Temos trabalhado neste } \\
\text { sentido com a ajuda das empresas ao nível da adaptação dos planos } \\
\text { curriculares (...) e têm surgido novas áreas de formação”. }\end{array}$ \\
\hline
\end{tabular}

Fonte: Elaborada pelos autores

De acordo com alguns participantes, nos dias que correm, ainda se assiste a uma considerável falta de reconhecimento do Ensino Profissional e áreas técnicas, pelo que urge criar um conjunto de estratégias que potenciem a mudança de mentalidades e, consequentemente, o reconhecimento social do Ensino Profissional e de algumas profissões que têm sido desvalorizadas. Esta atuação é, assim, percecionada como profícua para uma completa resposta às necessidades do tecido empresarial.

Outro dos tópicos mencionados pelos empresários diz respeito à falta de trabalho prático associada aos cursos, não só profissionais, mas também universitários, implicando (apesar da formação on job que as empresas realizam) um retorno tardio da atividade dos trabalhadores. Esta situação acaba por desencadear um desajustamento entre as competências dos trabalhadores e as necessidades das empresas daí que, no âmbito dos percursos formativos, tenha sido reforçada a importância de um equilíbrio entre a formação teórica e prática, fomentando um aumento das atividades em contexto empresarial.

Os estágios-emprego financiados pelos serviços públicos de emprego e formação profissional constituíram, igualmente, um dos temas abordados pelos representantes das empresas, tendo as intervenções incidido na morosidade dos processos. De facto, foi manifestada grande abertura à integração de estagiários do ensino profissional (curriculares e/ou profissionais), porém fica também patente a necessidade de criar uma estratégia que agilize este processo (e.g. após um estágio curricular - 3 meses, criar uma rápida resposta para a integração dos jovens num estágio-emprego - 9 meses).

Relativamente ao domínio das competências, à semelhança do que tem vindo a ser comprovado através de vários estudos, assiste-se a uma valorização das competências transversais (autonomia, responsabilidade, iniciativa, trabalho em equipa, línguas estrangeiras) em detrimento das competências técnicas, evidenciando-se mais uma vez um desfasamento entre as competências pessoais dos jovens e a realidade do mundo empresarial.

A oportunidade de reunir no mesmo espaço representantes quer de entidades locais de âmbito empresarial, quer de entidades com intervenção ao nível da qualificação da população, desencadeou uma importante dimensão: a cooperação entre as mesmas. Se por um lado assistimos à total disponibilidade das empresas para colaborar com as Escolas Profissionais no que concerne à criação de cursos voltados para as suas necessidades, por outro lado, surge a constatação de que esta complementaridade tem vindo a ocorrer, uma vez que são as 
próprias entidades de formação a mencionar que têm procedido à adaptação dos planos curriculares dos cursos em conjunto com as empresas, no sentido de aproximar os percursos formativos, o mais possível, às necessidades do mercado de trabalho. Ainda de salientar, por parte das entidades formadoras, o reconhecimento de que os cursos profissionais não são consentâneos com as reais necessidades das empresas, destacando-se o ensino tendencialmente teórico e, por outro lado, o esforço de algumas entidades no que se refere à implementação de novas áreas de formação, ajustadas às necessidades das empresas (e.g. mecatrónica automóvel, turismo, etc).

Outra das temáticas a merecer destaque neste trabalho prendeu-se com a intervenção de um representante dos serviços públicos de emprego e formação, a qual incidiu sobre os Jovens NEET (Not in Employment Education or Training) - jovens até aos 29 anos que não estão integrados em qualquer modalidade de ensino, formação ou mercado de trabalho -, procurando divulgar a iniciativa Garantia Jovem. Esta iniciativa, da responsabilidade do IEFP, vem reforçar a importância de uma metodologia de intervenção assente num trabalho de (re)construção de redes a nível local, integrando as entidades e os atores melhor posicionados e capacitados, para sinalizar e captar os jovens que se encontrem em situação de maior fragilidade. Neste contexto, a lógica deste trabalho em rede direciona-se para a conciliação de respostas ao nível da qualificação, da inserção e das transições.

De notar que, de acordo com dados de 2017, dos serviços públicos de emprego, o ensino básico é o nível mais representativo na estrutura de habilitações da população desempregada em Sintra (52,7\%), enquanto dados do ano anterior (2016) indicam que a taxa de desemprego dos jovens (inscritos nos serviços de emprego) atingia 1001 jovens (7.5\%) com idade inferior a 25 anos e 2382 jovens (17.8\%) na faixa etária dos 25-34 anos. O trabalho de diagnóstico por nós realizado no âmbito do projecto educativo local revelou claras preocupações, associadas a uma grande percentagem $(18,2 \%)$ de população residente com idades entre os 18 e os 24 anos que completou o $3^{\circ}$ Ciclo do Ensino Básico $\left(9^{\circ}\right.$ ano de escolaridade), mas que não se encontra a frequentar o sistema de ensino, assim como a uma taxa de retenção e desistência do ensino básico superior à média da região de Lisboa (AML) e do país e a uma taxa de transição/conclusão no ensino secundário inferior às unidades desejáveis de referência.

Por tudo isto se justifica a especial atenção que devem merecer os jovens afastados do sistema formal de educação, formação e emprego, Jovens Nem-Nem, principalmente, aqueles que estão ocultos nas estatísticas oficiais, dificultando a sua sinalização e aumentando o risco de marginalização e exclusão social. Todos estes indicadores reforçam as novas exigências colocadas ao município e aos diferentes parceiros que nele atuam, no que se refere ao aumento das qualificações de todos os jovens e ativos empregados e desempregados, tendo sempre em linha de conta o equilíbrio entre as necessidades das pessoas/famílias e as das dinâmicas socioeconómicas, numa lógica de trabalho digno.

\section{CONSIDERAÇÕES FINAIS}

Apesar do significativo esforço de qualificação da população, em todos os níveis, feito por Portugal, ao longo das últimas décadas, no sentido de recuperar o atraso que nos distancia de países mais desenvolvidos, a verdade é que a realidade ainda se distancia da situação de grande parte dos países da União Europeia, persistindo baixos níveis de qualificação. Tal facto, associado a elevadas taxas de abandono e saída precoce do sistema de ensino, acaba por dificultar substancialmente o acesso à formação e à aquisição e aplicação de novos conhecimentos, impedindo a criação de uma base sólida de competências e, consequentemente, desencadeando grandes dificuldades ao nível do envolvimento da população ativa em contextos de mobilidade profissional e reorientação das orientações 
económicas predominantes.

Indubitavelmente, a formação profissional de jovens, associada ao mundo do trabalho, tem de adaptar-se à evolução do mesmo, designadamente no que respeita aos objetivos e conteúdos. Tal como ficou demonstrado, as contribuições dos representantes das empresas do município em análise, apontam para a vontade de verem o ensino profissional encetar o desejável percurso, no sentido da adaptação dos percursos formativos às suas reais necessidades, não só ao nível das áreas de formação, mas também ao nível das competências técnicas e das competências pessoais e sociais (transversais). Sendo bem conhecido o que as empresas pretendem traduzir com este discurso, esta constatação aponta para a vontade de verem emergir processos formativos enquadrados com necessidades de recursos humanos adaptáveis às culturas empresariais e capazes de evoluírem na lógica das suas estratégias futuras.

Todavia, embora seja importante levar em consideração as exigências formativas das empresas, é imprescindível que os sistemas de formação potenciem um leque de competências e atitudes que possibilitem aos jovens integrar-se na vida ativa e favoreçam, no futuro, uma navegação profissional sustentada em projetos de vida informados, desafiantes e realistas, capazes de lidar com resiliência e criatividade com as constantes mudanças tecnológicas, sociais e culturais, conjugando dinamicamente, de acordo com a realidade e as possibilidades de mudança, saberes técnicos relacionais e emancipatórios.

Numa nova conjuntura, em que as mudanças aceleradas se constituem como regra, é essencial criar condições para ancorar a preparação dos trabalhadores no futuro e criar estratégias diferenciadas, encarando o profissional como um agente no processo de tomada de decisão e de construção de novas realidades, tendo sempre como premissa a necessidade de um contínuo envolvimento em práticas de educação e formação que se devem prologar e alargar longo e a todos os espaços da vida.

Partindo das declarações dos participantes no grupo focal, foi notória a preocupação quanto à falta de reconhecimento do ensino profissional e de profissões associadas a áreas mais técnicas. Evidentemente, estamos perante uma dimensão sobre a qual deverão ser tomadas medidas e ser definidas sólidas estratégias que promovam uma nova visão, visando a valorização e o prestígio da formação profissional. A elevada burocracia subjacente aos processos dos serviços públicos, ao representar para as empresas locais um dos entraves à dinâmica do recrutamento e seleção de estagiários, facilitando os seus processos de socialização profissional, deverá ser também objeto de reflexão, passando pela criação estratégias que melhorem a comunicação e agilizem todos os procedimentos.

Tendo em consideração todas as dimensões abordadas e analisadas pelas empresas e entidades de formação, não ficámos indiferentes à disponibilidade demonstrada para uma efetiva cooperação entre elas, traduzida pela complementaridade e adaptação dos percursos formativos, nas variadas vertentes, às reais necessidades das dinâmicas do trabalho naquele território. Neste sentido, importa reforçar a ideia e a necessidade de trazer novas lógicas de partilha de responsabilidades na articulação e otimização de meios e recursos, essenciais à concretização de práticas concertadas, alcançando o grande desígnio de um trabalho em rede local para a qualificação capaz de promover mudanças ao nível dos processos produtivos e do incremento contínuo de emprego de qualidade.

Paralelamente a outras estratégias de envolvimento e auscultação dos parceiros locais, todos os contributos resultantes deste momento reflexivo permitiram consolidar alguns princípios orientadores para a definição de um eixo estratégico com objetivos e ações consentâneas com as transformações ambicionadas no âmbito da qualificação da população. Do diagnóstico realizado, e atendendo à diversidade de oferta implementada no Município de Sintra, ficou demonstrada a necessidade de consagrar práticas de trabalho em rede, entre a autarquia, organizações educativas, jovens, famílias, empresas e associações, por forma a 
melhorar a informação, as práticas de orientação, os recursos necessários ao incremento da qualidade da formação e dos estágios e aumentar as possibilidades e oportunidades de emprego, de acordo com as expectativas e os projetos das pessoas. Revelou-se, igualmente, perentória a aposta num aumento significativo das atividades educativas e de formação para adultos, nomeadamente as unidades de formação de curta duração, aproximando-as a curto prazo do objetivo desejável de envolver, todos os anos, uma maior percentagem de pessoas adultas, com particular atenção aquelas que apresentam menores níveis de escolaridade e de qualificação e se situam em grupos etários mais elevados. Afigurou-se, ainda, determinante potenciar o envolvimento de mais trabalhadores em atividades de Educação e/ou Formação de Adultos, visando a elevação dos níveis de escolaridade e de qualificação da população empregada.

Entendeu-se, assim, que a capacidade de resposta aos desafios futuros deverá passar por uma adequação da oferta formativa e por uma atuação prospetiva, empenhada e responsável dos atores envolvidos na estrutura das ofertas formativas, promovendo, ao mesmo tempo, novas abordagens junto dos destinatários, incentivando-os a procurar as melhores opções de formação e informando-os, claramente, sobre as condições de empregabilidade.

De igual modo, fez parte das linhas de ação do projecto educativo local a promoção de uma maior aproximação entre as instituições de ensino e o tecido empresarial do território, solicitando junto destas a colaboração para a definição dos perfis e conteúdos formativos, bem como para a elaboração de programas e metodologias de formação. Procurou-se caminhar no sentido da criação de uma rede colaborativa potenciadora da construção de um território verdadeiramente comprometido com a qualidade de vida dos cidadãos e, consequentemente, com o sucesso dos seus percursos. Para isso, como também se percebeu, é incontornável que as políticas locais potenciem experiências educativas diferenciadas e espaços de interacção e debate, destinados a promover reflexões e acções problematizadoras, a partir e sobre o trabalho.

Face ao indubitável aumento da precariedade do emprego jovem, o projecto educativo local procurou, também, centrar a sua missão na criação de oportunidades para que os jovens que não estão a trabalhar, nem inseridos no sistema educativo/formativo e que abandonaram precocemente o sistema de ensino, concluam um percurso qualificante, por via do ensino profissional ou superior, implementando estratégias que promovam transições bem-sucedidas entre o sistema educativo/formativo e o mercado de trabalho.

A construção do Projeto Educativo Local de Sintra revelou-se uma notável oportunidade de criação de políticas locais de educação e formação, associando-as a determinadas opções de desenvolvimento, e consequentemente, aos recursos e dinâmicas existentes ou passíveis de ser mobilizadas e desenvolvidas no município. Neste contexto, o planeamento concertado - agentes educativos, empresários, outros parceiros - de uma oferta diversificada e adaptada às necessidades do município em termos de ensino profissional e tecnológico, a implementação de um sistema de orientação vocacional que preveja e evite situações de insucesso e de abandono do percurso escolar e formativo por parte da população jovem, afigurou-se determinante, face à nova visão para a educação do território.

\section{REFERÊNCIAS}

ALCOFORADO, Joaquim Luís; VIEIRA, Cristina; MOIO, Isabel. Revisitando as Políticas de Educação e Formação de Adultos dos Últimos 20 Anos em Portugal. In: DANTAS, Tânia Regina; LAFFIN, Maria Hermínia Lage Fernandes; AGNE, Sandra Aparecida Antonini (Eds.). Educação de jovens e adultos em debate. Pesquisa e formação. Curitiba: CRV, 2017. p. $17-40$. 
ALCOFORADO, Luís. Competências, Cidadania e Profissionalidade: Desafios e Limites para a Construção de um Modelo Português de Educação e Formação de Adultos. Tese de Doutoramento. Faculdade de Psicologia e de Ciências da Educação da Universidade de Coimbra, Coimbra, 2008.

ALCOFORADO, Luís; CORDEIRO, António Rochette; FERREIRA, António Gomes. Territórios, Comunidades Educadoras e Desenvolvimento Sustentável. In: CORDEIRO, António Rochette; ALCOFORADO, Luís; FERREIRA, António Gomes (Eds.). Territórios, Comunidades Educadoras e Desenvolvimento Sustentável. Coimbra: Departamento de Geografia, Faculdade de Letras da Universidade de Coimbra, 2014. p. 7-14.

ALCOFORADO, Luís; FERREIRA, António Gomes; MOUTINHO, José. A Educação Profissional na Educação Básica em Portugal: reflexões a partir de um estudo de caso. Revista Espaço do Currículo v. 6, n. 2, p. 261-279, 2013.

ALCOFORADO, Luís; PREGUIÇA, Cláudia; FRIAS, Mafalda. A Emergência de Novas Profissionalidades na Educação e Formação de Adultos em Portugal: necessidade e consolidação do perfil do mediador na perspetiva dos diferentes agentes. In: BARROS, Rosanna; LIMA, Paulo Gomes; AZEVEDO, Márcio (Eds.). Rumos da Educação e Formação de Jovens e Adultos em Portugal e no Brasil: um balanço comparado de políticas e práticas. Natal: Editora IFRN, 2020. p. 132-152.

AZEVEDO, Joaquim. A Educação Tecnológica nos Anos 90. Porto: Edições ASA,1991.

CERQUEIRA, Maria de Fátima; MARTINS, Alcina Manuela. A Consolidação da Educação e Formação Profissional na Escola Secundária nos últimos 50 anos em Portugal. Revista Lusófona de Educação, n. 17, p. 123-145, 2011.

CRUZ, Helena Cristina; ALBUQUERQUE, Cristina Pinto; ALCOFORADO, Luís. A formação profissional: da qualificação à "gestão do não trabalho". Mutações nas trajetórias e identidades dos técnicos de serviço social no sistema de formação profissional português. In: ESTRELA, Teresa et al. (Eds.). Formação Profissional: Investigação Educacional sobre teorias, políticas e práticas. Atas do XX Colóquio da Association Francophone Internationale de Recherche Scientifique en Education. Lisboa: EDUCA/Secção Portuguesa da AFIRSE, 2013.

DIAS. Ensino profissional: razões para a sua escolha: um estudo de caso. Dissertação de Mestrado. Universidade Católica Portuguesa, Braga, 2012.

FREIRE, Paulo. Educação e mudança. Rio de Janeiro: Paz e Terra, 1983.

KRUEGER, Richard; CASEY, Mary. Anne. Focus groups: A pratical guide for applied research. 4 ed. California: Sage, 2009.

LESOURNE, Jacques. Éducation et société: Les défis de l'an 2000. Paris: Éditions la Découverte e Jornal Le Monde, 1988. 
MADEIRA, Maria Helana. Ensino Profissional de Jovens Um Percurso Escolar Diferente para a (Re)Construção de Projetos de Vida. Revista Lusófona de Educação, n. 7, p. 121-141, 2006.

MARQUES. As Escolas Profissionais: um modelo de formação. Inovação, n. 3, p. 45-52, 1990.

MORGAN, David. Focus group. Annual Review Sociology, n. 22, p. 129-152, 1996.

PARDAL, Luís; VENTURA, Alexandre; DIAS, Carlos. O Ensino Técnico em Portugal. Aveiro: Universidade de Aveiro, 2003.

PELIZ, Marina. O Ensino Profissional de Nível Secundário em Portugal, 2000-2014. Quase-Mercado e Isomorfismo. Lisboa: ESCXEL, 2014.

PIVETEAU, Vincent. Territoire-formation-développement: un triptyque à revisiter par temps changeant. Education Permanente, n. 185, p. 7-13, 2010.

PORTUGAL. Decreto-Lei nº 26/89, de 21 de Janeiro de 1989a. Diário da República: ${ }^{\circ} 18$, I Série. Ministério da Educação, 1989.

PORTUGAL. Decreto-Lei no 286/89, de 29 de Agosto de 1989b. Revisão Curricular do Ensino Básico e Secundário, 1989.

PORTUGAL. Decreto-Lei no 46/86, de 14 de Outubro de 1986. Lei de Bases do Sistema Educativo, 1986.

PORTUGAL. Resolução do Conselho de Ministros nº 173/2007. Diário da República ${ }^{\circ}$ 214, I Série. Presidência do Conselho de Ministros, 2007.

RODRIGUES, Liliana. Ensino Profissional, o Estigma das Mãos Mais do que a Cabeça. Mangualde: Edições Pedago, 2011.

SOUZA, Dalva garcia de. A Formação Profissional como Estratégia para o Desenvolvimento Local: a construção endógena do conhecimento no senai/dr-ms. 2011. Dissertação apresentada ao Programa de Pós-graduação em Desenvolvimento Local. Universidade Católica Dom Bosco, Campo Grande, 2011. 